\title{
CONCILIACIÓN ENTRE EL UNIVERSO, EL SER HUMANO Y LA EDUCACIÓN UNIVERSITARIA
}

\author{
Ileana Castillo Cedeño ${ }^{1}$ \\ Vicedecana del CIDE-Universidad Nacional \\ Heredia, Costa Rica
}

Recibido: 12 de febrero, 2008 - Aprobado: 10 de mayo, 2008

\begin{abstract}
Resumen: Esta reflexión surge de la experiencia vivida como estudiante y como académica universitaria, esperanzada en la idea de que la Educación Superior, tiene la oportunidad y el potencial para reencantar y vitalizar los procesos educativos formales desde el paradigma de la complejidad, que asume los vínculos ineludibles entre el ser humano y el Universo.
\end{abstract}

Palabras clave: Educación universitaria, ser humano, Universo.

\begin{abstract}
This reflection emerges from the experience I have lived as a student and as an academic university professor with the hope that superior education can have the opportunity and potential to renew and vitalize the formal educational processes, from the point of view the paradigm of complexity wich assumes the close relation between the human being and the Universe.
\end{abstract}

Key words: University Education, mankind, Universe.

\section{Introducción}

En el umbral del siglo XXI, seguimos percibiendo la presencia de comprensiones monocordes y fragmentarias, con respecto al Universo, al ser humano y a la educación, como parte de la herencia histórica y cultural que tan fuertemente impactó la visión del mundo y la vida durante los siglos XVI y XVII, XVIII y XIX; tal presencia se centralizó por concebir al mundo y a la persona como máquinas, estableciendo uniformidad entre las leyes que rigen la naturaleza

\footnotetext{
Doctora en Mediación Pedagógica. Su formación inicial fue en educación con énfasis en educación preescolar. Máster en Psicopedagogía. Egresada de Doctorado en Diseño Curricular y Evaluación Educativa de la Universidad de Valladolid, España. Ha laborado en distintos niveles del sistema educativo desde preescolar hasta el universitario, así como también, con diversas poblaciones entre las que destacan adolescentes de comunidades en desventaja social y adultos mayores. Actualmente, se desempeña como investigadora y docente. Forma parte del equipo de apoyo de los Programas de Diseño y Gestión Curricular y el de Evaluación y Desarrollo Profesional de la Dirección de Docencia de la Universidad Nacional. ileanac@racsa.co.cr
} 
física, con las de la humana, aspecto que se hizo latente en los procesos formativos, desde donde se ha gestado una danza sutil de poder, control y sometimiento.

Desde muy temprana edad, nos han sumergido en experiencias de educación formal, las que, muchas veces, lejos de potenciar el pensamiento crítico, creativo, reflexivo y liberador, lo ha oprimido al punto de anular la naturaleza sensitiva e intuitiva, negando su valor en el desarrollo de la inteligencia y la acción.

Este problema se va agudizando conforme la persona avanza en los procesos educativos, principalmente, cuando llega a la etapa de la educación universitaria. Aquí, por lo general, existe una preocupación desbordante por diseñar planes de estudio que permitan a las personas un excelente manejo disciplinar para, inocentemente, desempeñarse con éxito en el mundo laboral.

En este sentido, Laing, citado por Capra (1982), señala que: “Desaparece la vista, el oído, el sabor, el tacto y el olfato y junto con ellos se van también la estética y el sentido ético, los valores, la calidad y la forma, esto es, todos los sentimientos, los motivos, el alma, la conciencia y el espíritu" (pp. 57-58).

Ciertamente, vivimos en una época en la que el avance de la ciencia y la tecnología ha traspasado las fronteras de nuestra imaginación, indicándonos que se requiere de un conocimiento profundo en las diferentes áreas del saber para corresponder, de forma coherente, con las exigencias. No obstante, muchas veces, estos cambios nos dejan perplejos y desconcertados, al experimentar que esa evolución, pensada para promover el desarrollo del talento humano, ha generado, también, un vacío existencial, sin precedentes en la historia de la humanidad, cuyos efectos se revierten en un deterioro de la salud del ser humano y de nuestro planeta.

La visión radical y absolutista del mundo y de la vida, impulsada, en gran medida, por el sistema educativo tradicional, ha engendrado una gran desesperanza, de la cual somos testigos, víctimas y cómplices.

Esta percepción, precisamente, por sus graves consecuencias, exige la preparación de personas competentes, no sólo desde el punto de su disciplina, sino, ante todo, desde una visión holística, que tiene que ver con el conocimiento y la autovaloración personal, la 
apreciación de los otros y las otras como auténticos sujetos de derechos, con los que se convive en contextos social, histórico, cultural, político, económico, ético y estético, que exigen diálogo permanente con el mundo y la vida, inexorablemente vinculada con la creación universal. Somos, entonces, sólo una pequeña parte del macrocosmos, en donde todo está en constante renovación e interconexión, y eso debe ser también parte del cultivo profesional.

Hoy, ante la amenaza de destrucción que vive la humanidad, producto de su poca conciencia sobre su vinculación con el Universo, parece ampliarse el discernimiento de que si desde la educación no se reflexiona y se promueve el compromiso con la vida en todas sus expresiones, podemos, como especie, desaparecer, tal y como lo advierte Kakú (1998).

De ahí, el aporte que debe brindar la educación universitaria, a la cual se le exige una fuerte dosis de creatividad, para abrir nuevas posibilidades y esperanzas; claro está, esto no es una tarea fácil. Briggs y Peat (1999) señalan que: "La creatividad se cuece a fuego lento en los sudores de las cabañas, en la exploración de la incertidumbre, en el sacrificio de lo que no es familiar" (p. 30).

\section{Educación superior y su compromiso con la complejidad de la vida}

Ser protagonistas en el análisis de los procesos de crisis, de caos e incertidumbre que experimentan nuestras sociedades, es una de las misiones que tienen que asumir las universidades como gestoras de nuevos sentidos, aspecto relacionado con los valores y la espiritualidad, entendida como transformación del ser, más allá de lo exterior. Boff (2001) considera que: "Hoy día, la singularidad de nuestro tiempo reside en el hecho de que la espiritualidad está siendo descubierta como una dimensión profunda del ser humano, como el momento necesario para la plena eclosión de nuestra individualización y como espacio de paz en medio de los conflictos y desolaciones sociales y existenciales" (p. 20).

La Universidad está comprometida con la búsqueda permanente de espacios de reflexión académica $y$, por qué no, de contemplación, que permitan a docentes, administrativos y estudiantes, introyectar una visión que fortalece la importancia de la vida. Esto, desde luego, 
exige un compromiso compartido, en el que el diálogo se torna como la estrategia esencial para entender el momento crucial que encarna nuestra historia. Según Capra (1982), lo anterior implica una responsabilidad que tenemos todos y todas como individuos, como miembros de una civilización y como ecosistema planetario.

Muchas reformas en los niveles curricular y administrativo, en el seno de las instancias de educación superior, no trascienden el discurso. Sin embargo, también existen instituciones que, claras en su misión y visión social y su compromiso con las nuevas generaciones y con el Universo, en general, desarrollan proyectos importantes en el ámbito de la investigación, la docencia, la producción y la extensión, en los que se apunta a la dignificación de la vida en todas sus dimensiones y manifestaciones.

Entre los principios teóricos, epistemológicos y axiológicos para los que fue fundada la universidad y su vinculación con las nuevas tecnologías de la información y el conocimiento, la Universidad Nacional de Costa Rica, ha propuesto en el marco mayor de su Plan Global Institucional 2006-2011, un modelo pedagógico, desde el cual se cultiva el respeto a la diversidad en todas sus expresiones, el compromiso con la igualdad de oportunidades y la construcción de sociedades más justas y equitativas, la formación de profesionales solidarios y comprometidos con el bienestar social, la formación del espíritu investigador y la creatividad, entre otros aspectos.

Es así, como la Universidad Nacional ha organizado encuentros académicos en los que se reflexiona y comprende que existe una cultura educativa heredada, que se ha encargado de amordazar las capacidades expresivas de la persona, aniquilando su genialidad innata, la inspiración creadora, estética y transformadora, es decir, la voz de la existencia. Este reconocimiento reta el pensamiento e impulsa a la acción transformadora.

El siglo XXI exige que las Universidades asuman, en coordinación con otras entidades gubernamentales y no gubernamentales, el principio de complementariedad, que propone un diálogo abierto entre subjetividades y entre disciplinas; asumiendo el paradigma de la complejidad, aventurándose por las vías de la interdisciplinariedad y los contrastes. Según Torres (2000) 
(...) apostar por la interdisciplinariedad significa defender un nuevo tipo de persona, más abierta, flexible, solidaria, democrática y crítica. El mundo actual necesita personas con una formación cada vez más polivalente para hacer frente a una sociedad donde la palabra cambio es uno de los vocablos más frecuentes y donde el futuro tiene un grado de imprevisibilidad como nunca en otra época de la historia de la humanidad (p. 48).

Estos esfuerzos tendrían que convertirse en la plataforma de concertación desde donde se asume la complejidad, la divergencia y la incertidumbre, como ingredientes imprescindibles para la formación y la construcción de nuevas sendas.

En opinión de Gelb (1999), se está en la obligación de restablecer la armonía entre la mente, el cuerpo y el espíritu; esa tríada que reconoce el expansivo potencial particular, para ir bordando realidades más afectuosas y configurar mapas personales y sociales inclusivos y solidarios.

Si todos los promotores del aprendizaje en el ámbito universitario nos preocupamos por comprender los nexos entre la comunicación, la participación y la liberación, se pueden engendrar nuevas posibilidades más allá de la reproducción y la perpetuación de patrones, y de acciones puntuales y aisladas.

Es urgente aventurarnos por las líneas de los contrastes, las cuales son totalmente válidas y necesarias, para formar seres capaces de asumir riesgos, de emprender retos que incluyan como compromiso, la transformación personal y social. Ante todo, es necesario tener presente que parte inherente a la función formadora, es despertar el pensamiento divergente, proclive al cambio, desde el cual se llegue al entendimiento y a la liberación. Cabe recordar que, tal y como lo señala Freire (1965), la educación debe ser práctica de la libertad mediante la fuerza creadora del diálogo, que es el que permite la aclaración de conciencias y posición en y sobre el mundo, para transformarlo.

En torno a esa práctica de la libertad, algunas investigaciones relacionadas con la física cuántica, la teoría de la relatividad y del caos, nos permiten comprender que la educación universitaria tiene que ampliar más su perspectiva, con una configuración profunda y compleja que involucra revolución del pensamiento, en el que se reconoce la indivisibilidad del Universo y del ser humano. 
La formación universitaria tiene el compromiso de otorgar al disentir argumentativo, una parte relevante de la formación de estudiantes, académicos y personal administrativo. Esto implica una decisión política arraigada en principios humanistas. No se trata de formar para oponerse y obstaculizar, sino para dar paso a un pensamiento reflexivo y crítico que, compartidamente, permita ensayar y trazar otros puentes que nos acerquen a realidades más amorosas.

Es preciso que la humanidad asuma que la esencia de lo esencial, no se encuentra en las teorías o saberes, como muchas veces se cree, sino que esos conocimientos se complementan con procedimientos ajustados a las características propias del colectivo que lo construye y reconstruye. La formación universitaria, tiene que direccionarse en términos de legitimar actitudes y valores fundamentales, más allá de lo visible y de lo cuantificable.

Irrefutablemente, hay que penetrar en el misterio profundo que entraña la vida, comprender que lo más importante en el ámbito educativo son las interconexiones, los detalles sutiles, que, al fin y al cabo, son los que le otorgan legitimidad a los principios educativos planteados para el siglo XXI: aprender a conocer, aprender a hacer, aprender a ser y aprender a convivir (Delors et al.1996).

Es necesario mantenerse en actitud dispuesta a recorrer otras rutas y aventurarse en lo desconocido, desprenderse de las certezas y dar paso al aprendizaje auténtico. Tal y como lo señalan Briggs y Peat (1999), para sacrificar el afán de control y vivir de forma creativa, es necesario poner atención a los matices sutiles y a los diferentes órdenes irregulares que nos rodean. Es preciso aceptar y vivir la incertidumbre, es en ésta donde encontramos nuestro potencial creativo.

De acuerdo con Cosachov (2000), “(...) lo creativo es aquello que se deshace para volverse a hacer, lo que aparece para volver representado en otra forma, se vuelve a desvanecer y se rematerializa, y, así, infinitamente" (p. 17). Eso implica transgredir los límites impuestos a nuestra razón y a nuestros afectos, despojarnos de ataduras y convertirnos en cocreadores de nuevas realidades. 
Si alcanzamos introyectar esta visión en la formación profesional, lograremos formar seres humanos capaces de valorar las múltiples opciones que existen para responder, con sabiduría, a las provocaciones que les presenta la vida.

Según Briggs y Peat (1999): “La verdad y el caos están unidos. Vivir con dudas creativas significa entrar en el caos para descubrir que la verdad no puede medirse con palabras" (p. 29). Una educación dialéctica, es aquella que permite participar, vivamente, en la búsqueda de la libertad. Gozoso el ser humano en la trama del conocimiento, puede ensanchar sus niveles de emancipación y aprender a coquetear con la vida, valorándola como aprendizaje con sentido.

Esto nos lleva a pensar que la educación superior no sólo se debe ocupar del desarrollo de la mente, sino que tendría que contemplar el impulso del espíritu. Quienes estamos dedicados al arte de educar, necesitamos trabajar más en esa dirección, para poder apostar a la conformación de un mundo mejor para todos los seres que habitamos en este planeta, el cual, a su vez, forma parte de un Universo infinito.

Tal y como lo señala Assman (2002), reencantar la educación significa propiciar ecologías cognitivas, mediante ambientes de aprendizaje que propicien la construcción de conocimientos plurivalentes. Implica intentar comprender la humanidad de la humanidad como lo afirma Morin (2003), Ilena de encuentros y desencuentros. La universidad, entonces, tiene como deber crear redes afectivas, que permitan la formación de comunidades de aprendizaje valerosas y comprometidas con la vida.

Es obligatorio promover el contraste y la diversidad de experiencias y de cosmovisiones, esto es lo que permite llegar a un diálogo penetrante con el mundo, desde donde inicia cualquier transformación. Esta ética profunda, reconoce la identidad universal.

La educación se enfrenta a la apasionante tarea de formar seres humanos, para quienes la creatividad y la ternura son necesidades vitales y elementos que definen los sueños de felicidad individual y social (Assman, 2002).

Incuestionablemente, un proceso educativo así pensado y desarrollado, que contribuya a fortalecer los vínculos entre el ser humano y el Universo, representa una de las más delicadas funciones de la humanidad: la formación de profesionales para los que la vida tiene sentido más allá de lo bancario. 
Como sociedades aprehendientes, nos corresponde buscar redes de apoyo para elevar los niveles de tolerancia y de respeto. Assman (2002), nos invita a actuar y a llenar la vida educativa de placer y de ternura, para lo cual la acción comunicativa es una excelente estrategia pedagógica.

Según Habermas (1987), la acción comunicativa, es esa "capacidad de aunar sin coacciones y de generar consenso que tiene un habla argumentativa, en que diversos participantes superan la subjetividad inicial de sus respectivos puntos de vista y a merced de una comunidad de convicciones racionalmente motivada; se aseguran, a la vez, la unidad del mundo objetivo y de la intersubjetividad del contexto en que se desarrollan sus vidas" (p. 27).

Lo anterior nos lleva a reflexionar sobre el valor de la intercomunicación, y la importancia de caminar en compañía de nosotros mismos y de otras personas y seres vivos. Sin duda, ese proceso de coevolución se desarrolla a un paso más lento, pero nos aseguramos de tejer redes y dejar huellas que nos permiten encontrar o reencontrar formas de actuación más holísticas y ecológicas.

La educación superior tiene la extraordinaria oportunidad de educar para lo trascendente, eso forma parte de la complejidad. Gallegos (1999) reconoce la espiritualidad como "la experiencia directa de la totalidad, en la que el ser humano reconoce el orden fundamental del universo y su identidad con ese orden. Amor universal, compasión y libertad incondicional son la naturaleza de la espiritualidad (p. 18). Quizás, éste sea el secreto para reencantar y vitalizar los procesos educativos que deben, a su vez, ser procesos de encuentro y de sentido vital.

Desde la docencia, la investigación, la extensión y la producción, toda universidad que asuma con seriedad su compromiso universal, tiene que engendrar esperanza, ésta es el emblema que debe caracterizar el alma de la educación, tal y como lo señala Freire (1993). Todos los implicados en los procesos educativos en el nivel universitario, estamos llamados a ser defensores inclaudicables de la libertad, sembradores de esperanza. En este sentido, el autor la concibe como una necesidad ontológica, como una esperanza crítica, justa, fundamentada en la verdad y el bien común.

Es importante que nos reconozcamos como esa masa crítica que requieren nuestras sociedades para propulsar el cambio, la cual, necesariamente, tiene que estar en consonancia 
con el trabajo colaborativo, crítico y responsable, en el que se concibe a la persona como arquitecta de su existencia y de su ciudadanía mundial.

Es trascendental que repensemos nuestra función social. No podemos dormirnos en las charcas pantanosas donde se han quedado muchos, pues corremos el riesgo de convertirnos en lo que Rodríguez Rojo (1997) denomina muertos vivientes, cadáveres felices, porque, según él, cuando un ciudadano o ciudadana ha perdido la capacidad de manifestarse civilmente en contra de las injusticias de un sistema, ha muerto.

\section{Referencias}

Assmann, H. (2002). Placer y ternura en la educación. Madrid: Narcea.

Boff, L. (2001). Espiritualidad. Un camino de transformación. Río de Janeiro: Editora Sextante.

Boff, L. y Betto, F. (1996). Mística y espiritualidad. Madrid: Editoral Trotta.

Briggs, J. y Peat, D. (1999). Las siete leyes del caos. Las ventajas de una vida caótica. Barcelona: Revelaciones.

Capra, F. (1982). El Punto Crucial. Buenos Aires: Troquel.

Cosachov, M. (2000). Entre el cielo y la tierra. Un viaje por el mapa del conocimiento. Buenos Aires: Biblos.

Delors, J. (Coord.). Al Mufti, I., Amagi, I., Carneiro, R., Chung, F., Geremek, B., et al. (1996). La educación encierra un tesoro. (Informe a la UNESCO de la Comisión Internacional sobre la educación para el siglo XXI). Madrid: Santillana Ediciones UNESCO.

Freire, P. (1993). Pedagogía de la esperanza: un reencuentro con la pedagogía del oprimido. México D. F.: Editorial Siglo XXI.

Freire, P. (1965). La educación como práctica de la libertad. Medellín: Ediciones. PEPE.

Gallegos, R. (1999). Educación holista. Pedagogía del amor universal. México: Pax.

Gelb, M. (1999). Inteligencia genial. 7 principios claves para desarrollar la inteligencia inspirados en la vida y obra de Leonardo da Vinci. Bogotá: Norma. 
Habermas, J. (1987). Teoría de la acción comunicativa. Madrid: Taurus.

Kakú, M. (1998). Visiones. Madrid: Editorial Debate.

Morin, E. (2003). Método V. La humanidad de la humanidad. La identidad humana. Madrid: Editorial Cátedra Teorema.

Rodríguez Rojo, M. (1997). La perspectiva política de Paulo Freire. (Diálogos con Freire). Valladolid: s. e.

Torres, J. (2000). Globalización e interdisciplinariedad: el currículum integrado. (4a. ed). Madrid: Ediciones Morata. 